\title{
AVOIDANCE OF VASCULAR COMPLICATIONS ASSOCIATED WITH THE USE OF DOPAMINE
}

\author{
John B. Stetson and George P. Reading†
}

Dopamine is dihydroxyphenylethylamine. It is available for clinical use in the hydrochloride salt. The chemical structure is:<smiles>NCCc1ccc(O)c(O)c1</smiles>

In the body, dopamine occurs as an intermediate compound in the course of the synthesis of norepinephrine from phenylalanine. It may be unique among the catecholamines in that there is a direct effect on the alpha receptors, the beta receptors, possibly an indirect effect upon the beta receptors and also an effect on a specific dopamine receptor. The specific dopamine receptors can be blocked by butyrophenones and phenothiazines. The 1972 review by Goldberg ${ }^{1}$ reviews the pharmacological activity of the molecule and delineates potential clinical applications.

\section{Pharmacological actions}

Dopamine has a direct effect on the alpha receptors. Thus a patient who has been treated with reserpine will respond to dopamine infusions and over-dose of dopamine can be treated with phentolamine (Rogitine) or phenoxybenzamine. In clinical application, the direct beta stimulating effect may be of greater value to the anaesthetist. Cardiac output is increased with very little increase in the cardiac rate. There is occasional supraventricular tachycardia. Thirty-two years ago, the late Sidney Orth reported that dopamine induced ventricular tachycardia in four of five dogs under cyclopropane anaesthesia. ${ }^{2}$ On a theoretical basis, the use of dopamine has been proscribed during the employment of halogenated hydrocarbon anaesthetics. As many other safe techniques of administering an anaesthetic to the cardiac patient are available, these conditions may be academic.

Dopamine is considered to be a vasodilating agent, especially in low doses ${ }^{3}$ (1-2 micrograms per kilogram per minute). The total peripheral resistance is reduced, including resistance in the mesenteric, renal, coronary and cerebral blood vessels. The low dose has minimal cardiac effect. As the dose is increased from two to ten micrograms per kilogram per minute, cardiac output is increased due to the direct beta adrenergic cardiac stimulation. Above ten micrograms per kilogram per minute there is direct alpha adrenergic stimulation and arterial blood pressure

\footnotetext{
'John B. Stetson, M.D., Associate Anesthesiologist, Strong Memorial Hospital, The University of Rochester, School of Medicine and Dentistry, Rochester, NY, 14642. Ceorge P. Reading, M.D., Senior Associate Surgeon, Strong Memorial Hospital, Associate Professor of Plastic Surgery, The University of Rochester, School of Medicine and Dentistry.

$\nmid$ Present address: Presbyterian-St. Luke's Hospital, Chicago, Illinois 60612, U.S.A.
} 
increases as total peripheral resistance increases. At this point the renal blood flow, which had increased with low concentrations of the drug, may decrease. Because of this variation in response, Katz has noted recently that dopamine can be considered to be three different drugs, depending upon the dose administered. ${ }^{4}$

Because physicians tend to think of its vasodilating potential they may forget that dopamine can be a potent vasoconstrictor. Because of this, gangrene and sloughing may result if the drug is extravasated into tissues surrounding a blood vessel. The poor clinical condition of the average patient in whom dopamine is employed predisposes the patient to injury if the intravenous needle or catheter is improperly placed. The needle or catheter should always be placed into a very large vessel, so that there will not be pooling of the agent in one area nor an opportunity for extravasation. The veins of the dorsum of the hand and around the wrist or ankle should be avoided. Scalp vein infusions must be avoided.

What can be considered pioneering papers were published by McDonald, Goldberg and Tuttle in $1962^{5}$ and 1963. ${ }^{\circ}$ They employed dopamine to induce saluresis in four patients with severe congestive heart failure. Obviously these patients would have had poor peripheral circulation. This early work was followed by a publication ten years ago describing the use of dopamine for the treatment of hypotension in eleven patients, of whom six exhibited signs of shock. ${ }^{7}$ More recently, dopamine has been recommended for the treatment of myocardial dysfunction following open-heart operations $s^{8}$ and in the treatment of cardiogenic shock. $^{9}$

\section{Reports of Gangrene Associated With the Use of Dopamine}

In his article delineating the value of dopamine for treatment of patients with cardiogenic shock, Holzer and his associates ${ }^{9}$ reported a case in which the patient developed deep cyanosis of the fingertips. The cyanosis developed after 89 hours of dopamine therapy. The average dose was 14 micrograms per kilogram per minute. The therapy was discontinued but peripheral gangrene of both hands developed two days later. The authors do not state where needles or catheters were placed for administration of the drug. The patient was 60 years of age, had undergone a mitral valve replacement, and was receiving dopamine therapy because of renal failure. The dose employed is not stated, but the patient was given isoproterenol during the time of dopamine administration. More recently, Alexander and associates have reported on three additional patients; one from their institution and two others from their community. ${ }^{10}$ Alexander's patient was a 5l-year old man who had received a mitral valve prosthesis. The dose of dopamine was 10 micrograms per kilogram per minute for two days. On the second day there was confusion and the patient's feet appeared to be cyanotic. The location of the needle or catheter for administration of the drug is not noted. The dopamine was discontinued and the confusion cleared. The cyanosis of the feet and toes, however, progressed to gangrene. It was later discovered that the patient had previously suffered three episodes of frost-bite to his feet. Of the two other patients reported by Alexander and associates, one was a 61-year-old diabetic gentleman. The second patient was a 64-year-old male who developed a cold mottled hand following dopamine extravasation which was treated by administra- 
tion of phentolamine into the vein and into the skin of the involved area. The tissue colour improved within 90 minutes of this treatment and gangrene was averted. The authors concluded with a caution against "the use of dopamine in elderly patients with pre-existing vascular damage from arteriosclerosis, diabetes, Raynaud's Disease or frost-bite". Alexander's warning was reiterated by Greene and Smith. ${ }^{11}$ Their patient was a 69 -year-old male diabetic with myocardial infarction. The dose of dopamine employed was low ( 1.0 to $1.5 \mathrm{mcg} / \mathrm{kg} / \mathrm{min}$ ). This dose "maintained adequate blood pressure and urine output", but gangrene of the lower extremities developed "by the sixth day of treatment". Neither the extent of the gangrene, or the location of the infusion site were noted. The authors attempted treatment with sodium nitroprusside, but they did not avert "dry" gangrene. The product package insert notes "patients with a history of occlusive vascular disease (for example athero-sclerosis, arterial embolism, Raynaud's Disease, cold injury, diabetic endarteritis, and Buerger's Disease) should be closely monitored for any changes in colour or temperature of the skin in the extremities." The package insert also prescribes as antidote for peripheral ischaemia that the affected area be infiltrated liberally as soon as possible with 10 to $15 \mathrm{ml}$ of saline containing 5 to 10 mg phentolamine. Extravasation should be treated in a similar fashion.

Although not noted in the package insert, it would also seem reasonable to perform a sympathetic nerve block to the extremity, perhaps together with the infiltration of a local anaesthetic into the area of yasoconstriction. Application of a cold pack may decrease tissue metabolism in the constricted area until adequate perfusion has returned.

\section{Report of a CASE}

The patient, a 47-year-old white male, was transferred to Strong Memorial Hospital, Rochester, New York to be near his family home. Therapy indicated included general physical rehabilitation following over three months of bed therapy and rest for myocardial disease plus treatment and grafting of an area of ischaemic necrosis of the right forearm secondary to extravasation of dopamine.

The patient had previously led a vigorous life. He worked for a construction company and his hobbies included karate and sky-diving. He suffered the onset of adult type diabetes in 1968. This was treated with diet, chlorpropramide plus phenformin. He had smoked one and a half packages of cigarettes per day during his adult life. The patient admitted to a copious alcoholic intake prior to 1973. On January 14, while out of town on a construction job, he experienced severe chest pain. He was admitted to a local hospital the following day. At admission the diagnosis of an acute inferior wall myocardial infarction was made. During the next several days, there was a gradual increase in pulmonary oedema. On January 19 , the patient was transferred to a regional hospital with cardiac surgery facilities. There it was determined that the patient had an acute anterior wall infarction as well as an inferior wall infarction previously diagnosed. He had been placed on dopamine therapy before transfer to the regional hospital. At the time he reached the regional hospital, the dopamine infusion was being administered at the rate of $11 \mathrm{mcg} / \mathrm{kg} / \mathrm{min}$. His mind was obtunded and his legs were mottled with definite cyanosis of the skin over the knee caps. Pulmonary oedema was present and urin- 
ary flow was $14 \mathrm{ml} / \mathrm{hr}$. The trachea was intubated and controlled ventilation was begun with 80 per cent oxygen. An intra-aortic balloon was inserted to assist aortic blood flow. The patient's condition was stabilized, but he did not improve. On January 26 , he was taken to the cardiac catheterization laboratory where appropriate studies were done. Triple vessel disease was discovered. On January 27, the patient was brought to the operating room and a quadruple aortocoronary vein bypass graft was done to the diagonal, left anterior descending, posterior descending and posteriolateral branches of the coronary arteries. Dopamine therapy was continued at a rate of about $8 \mathrm{mcg} / \mathrm{kg} / \mathrm{min}$. On the morning of January 28 , the patient suffered ventricular fibrillation with circulatory arrest. Cardioversion was undertaken and was successful on the second shock. Following this the temperature rose to $40.5-41^{\circ} \mathrm{C}\left(103-104^{\circ} \mathrm{F}\right)$. Attempts were made to lower his temperature with aspirin and a cooling blanket. He was on cephalothin (Keflin) therapy and gentamicin was added after positive blood, urine and tracheal cultures. Cardiac output was poor. Urinary output had improved after transfer to the regional hospital. Following the operation it gradually decreased and finally stopped on the afternoon of January 28. Gentamicin was discontinued and replaced with chloramphenicol (Chloromycetin). In the afternoon of January 29 an intravenous infusion by scalp vein needle on the dorsum of his right forearm infiltrated. There was swelling, but blood returned into the line when the bottle was lowered. Dopamine, about $8 \mathrm{mcg} / \mathrm{kg} / \mathrm{min}$ was being administered through this line. Within two hours from the discovery of the swelling the infusion was withdrawn and $10 \mathrm{ml}$ of lidocaine 1 per cent solution with phentolamine $10 \mathrm{mg}$ was injected in the area.

During the following few days an area of necrosis of the skin and underlying tissue in the region of the infiltration became apparent (Figure 1).

By January 30 , the patient's condition had stabilized with an increase in urinary output. The intra-aortic balloon was removed on this date. The patient's lungs cleared and by February 3, he was removed from ventilator therapy. During his long confinement in bed, pressure ulcers had developed over the sacral area and left heel.

On March 16, the patient was transferred to the Strong Memorial Hospital in Rochester as noted above. At the time of transfer, his medications included digoxin, ethacrynic acid, furosemide, triamterene, isosorbide dinitrate, NPH insulin, and heparin.

Following admission he was treated with physiotherapy and conservative care of the pressure ulcers. Radiographs of the arm showed extensive calcification of the arteries and their secondary branches suggestive of Monckeberg's medial sclerosis.

Debridement of the necrotic area of the forearm was carried out on April 5, and again on April 9, under regional anaesthesia. At the second procedure it was apparent that much of the muscle mass of the extensor group was necrotic and after debridement the ulna was exposed with necrotic periosteum. The forearm was grafted with a split thickness graft on April 20, save for the exposed bone, and the patient was discharged on May 7 , with plans to readmit him for closure of the wound over the bare bone at a later date when his cardiac status had further improved. 


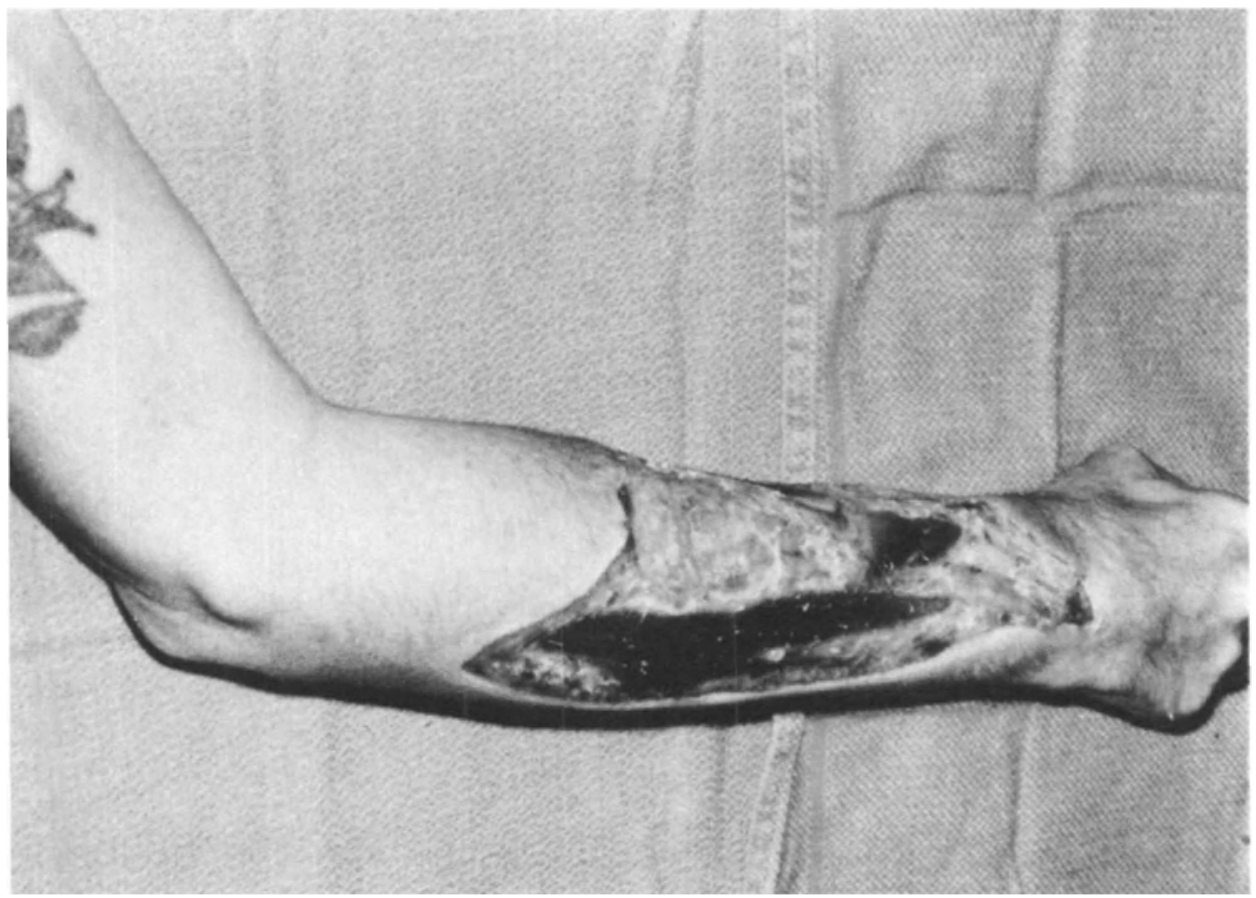

Figure 1. Right forearm April 8, 1976, showing extent of skin slough following first debridement.

\section{DisCUSSION}

That the patient is alive is a tribute to the care he received at the primary hospital and at the regional medical center. The necrotic area of the right forearm can be considered to be a small price to pay for life. The purpose of this report is to draw attention to this complication in the hope that it can be avoided by placement of catheters into major venous vessels. After extravasation of the dopamine containing fluid, the patient's physicians infiltrated the area with phentolamine and lidocaine. The treatment was proper and probably avoided greater injury. Perhaps if a catheter had been placed in the basilic vein in the upper arm or the femoral vein in the inguinal area, this nosocomial injury might have been avoided. Considering the multiple treatments the patient had received, including intra-aortic balloon therapy, access to a large vein was extremely difficult.

The finding of calcification of many arteries in this patient's forearm may not be related to the extent of necrosis, which is more extensive than expected. Many authors ${ }^{12,13}$ feel that the medial calcification of Monckeberg is not usually associated with intimal lesions and many patients have no evidence of occlusive arterial disease for many years following the discovery of extensive calcification.

Most patients who receive dopamine therapy have poor cardiac output and poor perfusion and are, therefore, very susceptible to local tissue necrosis. Our patient developed pressure ulcers of the sacral area and of one heel. For this reason extreme vigilance must be used in monitoring the site of infusion. Whenever 


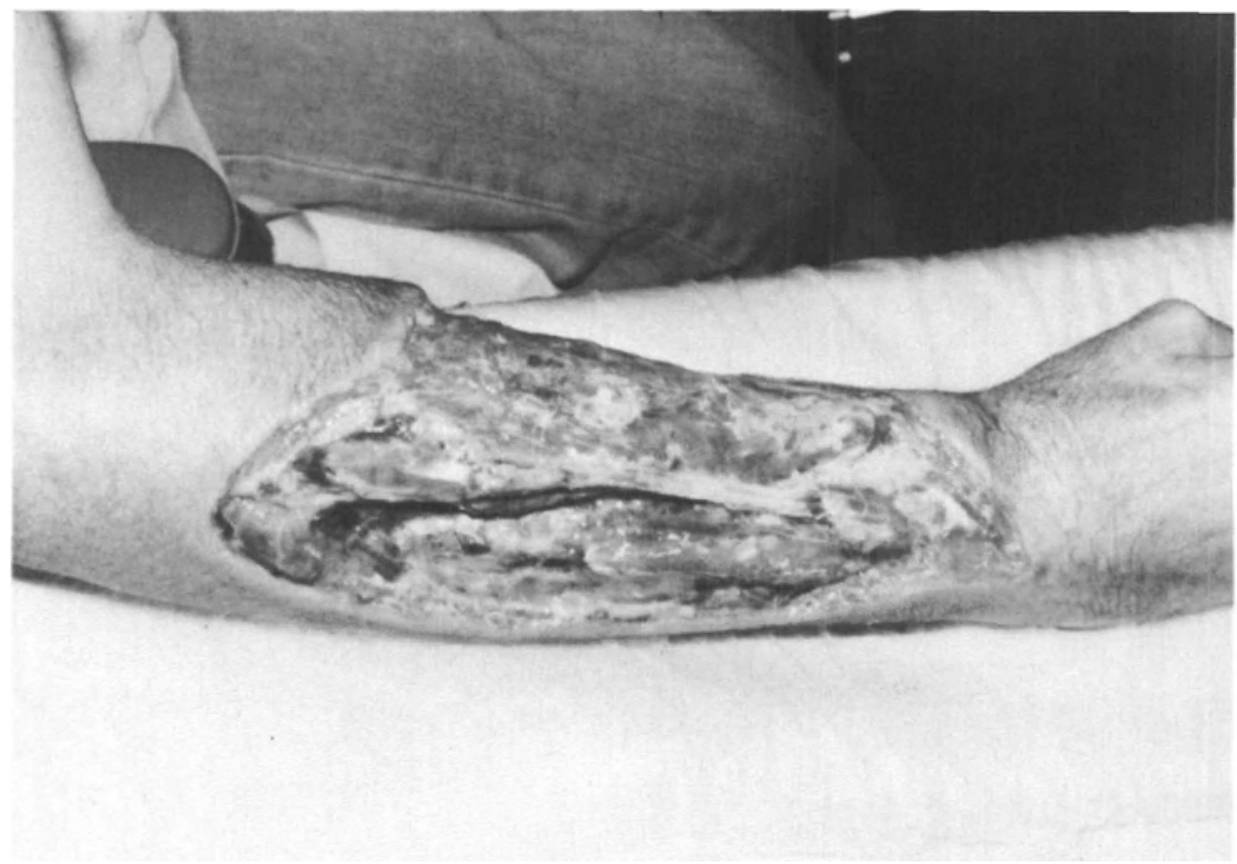

Figure 2. Forearm April 13, 1976, following second debridement, showing necrosis of muscles.

possible a catheter should be introduced into, or threaded to, a major vein. Although dopamine may be considered to be a vasodilating agent in low doses ( 1 $\mathrm{mcg} / \mathrm{kg} / \mathrm{min}$ ), as the dose increases the vasoconstricting potential of the agent increases. The fluid that extravasated in this patient probably contained about 8 $\mathrm{mcg} / \mathrm{kg} / \mathrm{min}$ of dopamine. This is very near the level of $10 \mathrm{mcg} / \mathrm{kg} / \mathrm{min}$ reported to have a direct alpha adrenergic stimulating effect. Local treatment of extravasation should be with infiltration and intravenous administration of phentolamine and probably infiltration with a local anaesthetic as well and the application of cold packs.

Dopamine is an excellent therapeutic agent but like any other potent drug it must be monitored carefully during administration.

\section{ACKNOWLEDGEMENT}

The authors appreciate the permission of Dr. Jules Cohen to report this case.

\section{SUMMARY}

Dopamine, dihydroxyphenylethylamine has three distinct actions depending on dosage. Low doses in the range of $1-2 \mathrm{mcg} / \mathrm{kg} / \mathrm{min}$ result in vasodilatation. Medium doses of $2-10 \mathrm{mcg} / \mathrm{kg} / \mathrm{min}$ increase cardiac output due to beta adrenergic action, while above $10 \mathrm{mcg} / \mathrm{kg} / \mathrm{min}$ a potent vasoconstrictor effect predominates. 
Because of this last action great care must be used to avoid extravasation of infusions of dopamine directly into the tissue.

Dopamine is a very useful agent but carries great potential to do local damage. Administration through a catheter placed into a large vein is recommended. Should extravasation occur, prompt infiltration of the area with phentolamine and a local anacsthetic, local cooling and regional sympathetic block may reduce the damage. The case is reported of a patient who suffered extensive necrosis in the forearm following local extravasation of dopamine.

\section{RÉSUMÉ}

La Dopamine a trois actions différentes en fonction de la dose administrée. Les petites doses, de l'ordre de 1 à $2 \mu \mathrm{g} / \mathrm{kg}$ amènent une vasodilatation. Des doses modérées, soit de 2 à $10 \mu \mathrm{g} / \mathrm{kg}$, produisent une augmentation du débit cardiaque par stimulation beta-adrénergique. Au-dessus de $10 \mu \mathrm{g} / \mathrm{kg}$, la Dopamine devient un puissant vasoconstricteur par stimulation alpha. C'est pourquoi il faut prendre toutes les précautions pour éviter une injection extra-vasculaire de Dopamine. On recommande l'administration au moyen d'un cathéter placé dans une grosse veine.

En cas d'extra-vasation, une infiltration locale de la région intéressée au moyen d'une solution de phentolamine et d'anesthésique local, l'application de compresses froides et un bloc sympathique peuvent contribuer à réduire les dommages.

Les auteurs rapportent le cas d'un patient ayant présenté une nécrose tissulaire étendue à l'avant-bras à la suite d'une injection accidentelle extra-vasculaire de Dopamine.

\section{REFERENCES}

1. Goldeneng, L.I. Cardiovascular and renal actions of dopamine: potential clinical applications. Pharmacol. Rev. 24: 1-29 (1972).

2. Orth, O.S., Stutzman, J.W., \& MEeK, W.J. Relationship of chemical structure of sympathomimetic amines to ventricular tachycardia during cyclopropane anesthesia. J. Pharmacol. Exp. Ther. 81: 197-202 (1944).

3. Smith, N.T. \& Conbascio, A.N. The use and misuse of pressor agents. Anesthesiology 33 : 58-101 (1970).

4. Katz, R.L. Panel: recent developments in pharmacology. Annual Meeting, American Society of Anesthesiologists, Inc., Chicago (October, 1975).

5. McDonald, R.H., Jr., Goldberg, L.I., \& Tuttle, E.P., Jr. Saluretic effect of dopamine in patients with congestive heart failure. Clin. Research 10: 19 (1962).

6. Goldeerc, L.I., MCDonald, R.H., Jr., \& Zimmerman, A.M. Sodium diuresis produced by dopamine in patients with congestive heart failure. N. Engl. J. Med. 269: 1060-1064 (1963).

7. MacCannell, K.L., McNay, J.L., Meyer, M.B., \& Goldeerg, L.I. Dopamine in the treatment of hypotension and shock. N. Engl. J. Med. 275: 1389-1398 (1966).

8. Rosenblum, R. \& Frieden, J. Intravenous dopamine in the treatment of myocardial dysfunction after open-heart surgery. Am. Heart J. 83: 743-748 (1972).

9. Holzer, J., Karliner, J.S., O’Rounke, R.A., Pitt, W., \& Ross, J. Effectiveness of dopamine in patients with cardiogenic shock. Am. J. Cardiol. 32: 79-84 (1973).

10. Alexander, C.S., Sako, Y., \& Mikulic, E. Pedal gangrene associated with the use of dopamine. N. Engl. J. Med. 293: 591 (1975).

11. Greene, S.I. \& Smith, J.W. Dopamine gangrene. N. Engl. J. Med. 294: 114 (1975).

12. Monckeberg, J.G. Uber die reine Mediaberkolkug der Extremitatenarteriein und ihr Verhalten zur Arteriosklerose. Virchows Arch. f. path. Anat. 171: 141 (1903).

13. Lansbury, J. \& Brown, G.E. The clinical significance of calcification of the arteries of lower extremities. Proc. Staff Meet., Mayo Clin. 9: 49-55 (1934). 